\title{
A Research Report on the Consumption View of Residents in Xinrong District under the Rural Revitalization Strategy
}

\author{
Yaqian Zhang, Xianlou Wu, Xin Weng* \\ Zhejiang Normal University, Jinhua, China \\ Email: ^1839515680@qq.com
}

How to cite this paper: Zhang, Y.Q., Wu, X.L. and Weng, X. (2021) A Research Report on the Consumption View of Residents in Xinrong District under the Rural Revitalization Strategy. Open Access Library Journal, 8: e7518.

https://doi.org/10.4236/oalib.1107518

Received: May 12, 2021

Accepted: June 13, 2021

Published: June 16, 2021

Copyright $\odot 2021$ by author(s) and Open Access Library Inc.

This work is licensed under the Creative Commons Attribution International License (CC BY 4.0).

http://creativecommons.org/licenses/by/4.0/

\section{(c) (i) Open Access}

\begin{abstract}
The "rural revitalization strategy" put forward in the report of the 19th national congress has pointed out the direction for the steady development of the rural economy. At present, the academic circle has done a lot of research on the five dimensions of the concrete implementation of the policy, but it has neglected the female consumption view under the influence of the policy. The female consumption view, which accounts for half of the rural population, has a great influence on the family and indirectly affects the implementation of the policy. Based on the strategy of the rejuvenating countryside as the background, from the gender Angle of view of Xinrong district women's consumption situation investigation, using a structured questionnaire and on-the-spot investigation method, point out that rural women such as blind consumption, impulsive consumption alienation, in view of the problem put forward concrete opinions: to advocate green consumption mode, reshape the female subject values, the mass media guide, intended to help Xinrong district rural revitalization strategy, provide decision-making reference for the relevant department.
\end{abstract}

\section{Subject Areas}

Consumer Behavior

\section{Keywords}

Rural Vitalization, Household Expense, Female Consumption

\section{Introduction}

\subsection{Purpose and Significance of the Topic}

Purpose of the topic: Through the investigation of the daily expenditure of fami- 
lies in Xinrong District, to understand the current development situation of rural areas and consumer expenditure under the rural revitalization strategy, to understand the consumption outlook of contemporary Chinese rural women under the change of status.

Significance of the topic: The rural revitalization strategy is an important policy formulated by the state for the work of "agriculture, rural areas, and farmers." The effective implementation of the policy is of great significance for promoting rural development and prosperity, driving the rural economy forward, and building a moderately prosperous society in an all-around way. In the two years since the Rural Revitalization Strategy was put forward, it has been obvious that the overall economic level of rural areas has improved, the income of farmers has risen, and the consumption of rural households has also increased.

In addition, with the country's economic prosperity and increasingly open society, women's status in the family and society has been improved again, and their consumption power has also been enhanced. But rural revitalization in its infancy, there is still a distance to achieve a comprehensive revitalization of the target distance, based on the survey of Xinrong district women's daily consumption, the rural women's current consumption can be a pluralistic understanding, as well as to the strategy of rejuvenating the country to carry out the situation have a multi-angle and serve as a reference for the further development of rural revitalization strategy.

\subsection{Research Methods and Data Sources}

This paper mainly focuses on micro-investigation and research based on the family. In the process of obtaining data, households are taken as the unit and structured electronic questionnaires are mainly used. The current situation of female consumption in Xinrong District, Datong City, Shanxi Province is taken as the research object, and the research method combines quantitative analysis and qualitative analysis.

In the early stage of writing the paper, the author first analyzed and summarized the relevant information, and formulated a questionnaire that was in line with the research, questionnaire design closely revolves around the research question, carries out an investigation on the current situation of female consumption in Xinrong District. From January 2020 to February 2020, the electronic questionnaire of "Survey Report on Household Expenditure" was distributed through the network, with a total of 21 questions for the convenience of subsequent statistics. The first 20 questions in the questionnaire were all given in a structured form. A total of 105 valid questionnaires were collected within one month after the questionnaire was issued, the sample size is reasonable and then a conclusion was drawn after data collection and analysis.

\subsection{Literature Review}

The rural revitalization strategy was put forward by the government in October 
2017, which is a relatively short time. Therefore, the research on the change of rural women's consumption concept under the influence of this policy is still in the neglected field. At present, the research contents related to this paper include the following three parts.

Research on rural revitalization policies, such as "Decoding Rural Revitalization", has made in-depth decoding of policies by interviewing well-known experts in sociology, economics, media and marketing, and enumerating practical examples from various domestic regions, such as Zhejiang and Shandong, as well as foreign countries such as Japan and New Zealand, from different perspectives. It provides different reference cases for the economic development of other regions. In addition, some questions and doubts are answered in the book, which is conducive to the understanding of policies from multiple perspectives. Wen Tiejun and Zhang Xiaode's “Ten People's Talks on Rural Revitalization” brings together the views of 10 experts in different fields to understand and read rural revitalization from the perspectives of strategic transformation, urbanrural integration and cultural orientation, which is helpful for rural development. Kong Xiangzhi's Nine Dimensions of Rural Revitalization and other books are all centered on rural revitalization policies. They provide detailed analysis of how policies can be effectively implemented in rural areas and put forward countermeasures to solve some rural problems, so that we have an in-depth understanding of rural revitalization strategies.

For example, Liu Wenyong's Study on the Influencing Factors of Residents' Consumption Decision-making from the Micro-perspective takes residents as the theme and makes a detailed analysis of the formation of the theory of residents' consumption decision-making in four stages from germination to development, as well as the factors affecting different behaviors of residents. In order for scholars to have a better understanding of the dominant factors affecting residents' consumption in different periods, some theories related to consumption are also improved in the book, which is convenient for scholars to reference and study [1].

The study of women consumption view, such as “women's consumption view" ms leung to women as the research object, the subject of women consumption is analyzed, such as women shopping to see the mood, like beauty, women dress up, etc., and at the weakness of the female, such as weak choice, vulnerable to encourage, gullible, etc., explains why women love shopping, It is convenient for scholars to understand female consumption psychology and consumption behavior, and how female group's consumption concept changes under the change of status.

The rural revitalization strategy was put forward at the 19th National Congress of the Communist Party of China (CPC) in a relatively short period of time. Therefore, researches on the changes of rural women's consumption attitudes under the influence of this policy still have neglected areas. The research contents related to this paper include the interpretation of the content and characteristics of rural revitalization policies, the suggestions for the reasonable and 
effective implementation of policies, the analysis of the factors affecting residents' consumption behavior, the introduction of women's status and women's consumption concept, etc. Through the analysis of the changes of women's consumption concept in Xinrong District under the rural revitalization strategy, this paper hopes to have a deep understanding of the current consumption situation of rural women and a more comprehensive cognition of the development status of rural revitalization strategy, so as to provide the reference for the better implementation of the policy.

\section{Investigation on Female Consumption in Xinrong District under the Rural Revitalization Strategy}

\subsection{Proposal of Rural Revitalization Strategy}

Rural revitalization is not only a matter of rural areas, but also an important policy related to national economic prosperity and national rejuvenation. "Rural prosperity leads to national prosperity, and rural decline leads to national decline" is an important law that has been followed by the evolution of Chinese civilization. As China's biggest national conditions, rural areas not only determine the unique path of modernization since modern times, but also determine the path of China's future development. The 21st century is the century of the great rejuvenation of the Chinese nation, to continue under the guidance of policy implementation of rural modernization and promote the development of the urban and rural integration, the promotion of social and economic vitality, protect rural hills and green, raising farmers' overall quality, promote the core values, to modernize the rural to move steadily, and let farmers have a stable source of income, to live a happy life.

Driven by the rural revitalization strategy, the number of poor people in China has been reduced year by year and people are living a richer life. With the joint efforts of all parties, the poverty alleviation work in Xinrong District has been fruitful. People's living environment has been improved, public facilities have been constantly improved, and incomes have increased steadily. The great achievements China has made in reducing poverty are of great reference significance to the development of domestic and even the world economy.

\subsection{Overview of New Prosperity Area}

Xinrong District is located in Datong City, Shanxi Province, with a total area of 1091.27 square kilometers and a total population of 118,000 people. It is adjacent to Fengzhen County, Yanggao County and Zuoyun County. Here beautiful mountains and rivers, fresh air, known as the "back garden of Datong" said.

In the early days of the founding of the People's Republic of China, Shanxi's economic development lagged behind. In 1952, the province's gross domestic product was only 1.6 billion yuan. Over the past 70 years, the People's Republic of China has witnessed continuous development and prosperity, and its comprehensive national strength has grown ever stronger. Similarly, great changes 
have taken place in Shanxi Province and gratifying achievements have been made. Under the joint efforts of the people of Shanxi, the total economic volume has been expanding, the economic growth rate has been accelerated, and the overall economy and per capita income have been greatly improved.

The report of the 19th National Congress of the Communist Party of China (CPC) put forward the strategy of rural revitalization and put the issues of "agriculture, rural areas and farmers" at the center. Guided by the policy and adhering to the new requirements of the new era, the whole province's economic aggregate has made another breakthrough and reached a new level in succession. From 2012 to 2016, the GDP of the whole province was over 1.2 trillion yuan. In 2017, the GDP of the region reached 1.552.84 trillion yuan; In 2018, it reached 1, 681.81 billion yuan. The nominal growth rate of the province increased by $11.28 \%$ compared with the same period in 2017. In 2019, the GDP of the province reached 1702.668 billion yuan, an increase of $6.2 \%$ over the previous year and 0.1 percentage point faster than that of the whole country. The economic growth rate of the province has exceeded that of the whole country for three consecutive years since 2017 [2].

In recent years, under the guidance of policies, Xinrong District Government has actively implemented the rural revitalization strategy and solved the problem of rural poverty. Under the joint efforts of the whole district, the economic aggregate of Xinrong District is expanding, the income channels of farmers are increasing, the poverty-stricken population is reduced, and the life of Xinrong District is increasingly affluent. In 2019, all 36 poverty-stricken villages were lifted out of poverty, 11, 386 people from 5475 households were lifted out of poverty, and the poverty rate dropped to 0.38 percent, a drop of more than 12 percentage points. The people are getting richer and leading a better life. The people's consumption concept has changed, the consumption mode has changed from subsistence to a comfortable life, and the forms of consumption have also become diversified [2].

\subsection{Analysis of Female Consumption in Xinrong District}

The author issued "about household spending report" of the questionnaire, surveyed the Xinrong district household spending, of respondents is given priority to with Xinrong district women, mostly distributed in the 20 to 30 years old this interval, it is because, in most families, daily expenses control by women, their family consumption is more understanding, This makes it easy to know the real consumption situation in each household. Through the analysis of the questionnaire, it can be seen that the overall consumption view of women in Xinrong District is mainly frugal consumption view. Influenced by China's traditional culture, most residents advocate frugality in consumption, especially nearly half of the residents' families are still in the situation of unstable income and do not have the condition of luxury consumption. The average monthly consumption of more than $70 \%$ of the families is almost the same as that of the plan, and the monthly consumption of $20 \%$ of the families is always higher than that of the 
plan. It can be seen that there is unreasonable consumption among the families in Xinrong District.

In the survey found that most of the women in Xinrong District's expenditure mainly focused on food, education, clothing, communication, medical treatment and other aspects. "Food is the life of the people", so the food expenditure has been in the high level in the total family expenditure, most of the new prosperity area farmers' family consumption is still the first food, Engel coefficient is still high. Compared with the consumption situation of previous years, the consumption level of residents in Xinrong District has been greatly improved, disposable income has also increased significantly, and the expenditure allocated to other aspects is gradually rising.

In Xinrong District households, the overall consumption view tends to be normal, but there is also the phenomenon of unreasonable consumption, in the survey of $20 \%$ of the family monthly consumption is always higher than the plan. Nowadays, with the rapid development of economy, all kinds of consumption temptations emerge one after another. Most young people have the concept of impulse consumption more or less. They will buy some things that they do not need when the store is offering discounts, or buy some things that they do not know about when the brand is promoting. Since the 21st century, more and more people in the consumption under the precondition of advocating freedom, economic freedom promoted the rapid growth of the consumer, but also appeared some unreasonable phenomenon of consumption, in a sense, the farmers' consumption has been growing faster to catch up with the speed of farmers' income growth, in the case of a limited income, unreasonable consumption makes farmers economic difficulties.

Consumption is a mirror of human development and progress. From the female consumption structure, it can be seen that the consumption scale of rural families is expanding, and the residents' life has entered the ranks of well-off and affluent from poverty. It can be seen that the construction of new countryside under the rural revitalization has made certain achievements, but at the same time, we should also pay attention to some unreasonable consumption phenomenon and call for rational consumption.

\section{Changes in Women's Consumption Outlook under Rural Revitalization}

\subsection{The Background of the Change in Consumption View}

Marx and Engels are all concentrated, Marx said that in order to "make history", people must be able to live. But in order to live, first you need food, clothing, shelter and other things [3]. Consumption is the basic premise of human survival. With the development of China's reform and opening up and the continuous development and prosperity of the market economy, the concept of consumption is also changing quietly.

In Zhang Huan's women get the world, this book introduces, in the 21st cen- 
tury, with the continuous economic development and increasingly open society, women's status in the family and society has been enhanced, and their consumption power has also been enhanced. People are beginning to refer to the 21st century as "her century", in which women play an increasingly important role in the economy and in the consumer world. According to statistics, Chinese women control 60 percent of the turnover of the domestic market and dominate 80 percent of the household consumption [4]. Most men are used to the responsibility of buying goods for the family to women, by women to buy the family needs, and this also caters to the interests of women, naturally assumed the responsibility of purchasing for the family, it can be seen that women have become the main force of the contemporary consumption tide.

When asked about the "favorite shopper in the family", the "hostess" and "child" were the most likely to vote. After the reform and opening up, put forward a series of policies to promote the economic development in our country, including rural policy strategies in promoting economic growth and material rich at the same time also led to the growth of the consumer, especially to twenty years old to 40 years old women at this stage is given priority to, their shift due to the economic conditions and the introduction of western consumption idea and changed the previous thrifty consumption view, Become the "favorite shopper in the family."

\subsection{Women's Changing Attitudes toward Consumption}

Zhang Huiling said that "female consumption can be understood from both broad and narrow perspectives. In a broad sense, female consumption refers to the consumption process in which women play one or more roles, that is, including the whole consumption process in which women are decision-makers, buyers or users. In a narrow sense, it refers to the consumption of women to meet their own needs." [5] Use its broad sense in the text.

Women play a variety of roles in the family, such as wife, mother, daughter, etc., so they also shoulder the responsibility of purchasing materials for the whole family. From small household articles, fuel, rice, oil and salt, clothing, shoes and hats, to big houses and cars, they all need to make purchasing decisions. The survey found that women in Xinrong District prefer food, clothing and children's education consumption, among which food consumption ranks first. From ancient times to modern times, the role of family "cook" husband is mostly undertaken by women, the preparation of three meals a day makes women become regular customers in vegetable shops and supermarkets. According to the field investigation in Xinrong District, $90 \%$ of the people in the market and supermarket are women, who are busy in the selection of three meals and the balanced matching of nutrition.

Driven by the policy, residents' consumption concept is also changing. Women in Xinrong District are no longer satisfied with full food in terms of food consumption, but pay more attention to the nutritional collocation of each meal. Haven't conditions, people's diet is monotonous, daily food is planted 
himself in harvest background, want to buy other things to go far, go to the fair city, you can buy the types of fruits and vegetables are very limited, especially in the winter average household can eat vegetables only autumn hoarding in the cellar, potatoes and carrots. Nowadays, with the development of economy, convenient shopping has become the norm. Vegetables and fruits are available all year round. You can buy whatever you want in the supermarket. With the development of convenient shopping, people are not only satisfied with food and clothing, but also pay more attention to nutrition and health in the choice of food. The local eggs, chickens and organic vegetables produced by rural households are in short supply.

In addition to spending on food, Xinrong women are also investing more in themselves, mainly in clothing and skincare products, clothing and skincare products consumption accounted for $36.79 \%$. In the past few years, people's concept is to eat enough and wear warm clothes, and there is no extra money to spend on clothes and skincare products. A piece of clothing will often wear for many years, where the broken sew a patch to continue to wear, except for the New Year we usually have few new clothes. For skincare products and toiletries is extravagant hope, only hand and foot crack cream at home. In recent years, with the development of economy, women's consumption concept has changed a lot. There are many women in clothing buildings and cosmetics stores. New clothes and skincare products are no longer luxuries. "Women are not shopping, or on the way to shopping", this sentence fully demonstrates women's love for shopping.

The development of e-commerce has opened a new world for women to shop and stimulated their enthusiasm for shopping. According to the survey of the daily shopping mode of women in Xinrong District, it is found that online shopping accounted for $76.19 \%$, and physical stores accounted for $73.33 \%$, online shopping has become the preferred shopping mode of modern women, which has surpassed the physical store shopping. Online shopping is favored by consumers, especially female consumers, because of its variety and low price. Another reason for the rapid development of online shopping is the convenience of modern mobile payment. The emergence of Alipay and WeChat has enabled modern people to make transactions at the touch of their fingers. In the questionnaire entitled "Your favorite way of shopping", 86.67\% of women in Xinrong District choose mobile payment, and mobile payment has become the first choice of female groups due to its convenience. From a national perspective, mobile payment has also witnessed amazing growth in recent years. In 2009, the Singles' Day was born, and the transaction volume of that year reached 52 million yuan. In the following decade, the sales volume of the Singles' Day has repeatedly broken new records, and in 2019, the transaction volume of the Singles' Day reached 268.4 billion yuan.

It is found in the survey that most families in Xinrong District invest in their children's education in the second place in the total consumption in recent 
years. Parents place their unfulfilled college dream on their children, hoping that they can win a good future through education. Now in addition to the daily school expenses for each child, most parents will arrange interest classes for their children on weekends, girls dance classes are mostly, boys are painting classes. At the same time that economic conditions are getting better, women's consumption concept is also changing, paying more attention to the all-around development of children's morality, intelligence, body, beauty and labor.

\subsection{Carry forward China's Traditional Consumption Virtues}

According to the survey, $41.9 \%$ of women in Xinrong District average monthly consumption of 1000 - 3000 yuan, $30.48 \%$ of women's monthly consumption of 3000 - 5000 yuan, the overall consumption level of women in Xinrong District is within a reasonable range. However, 43.81 percent of women answered "yes" to the question "whether you will buy something unnecessary at home during activities in shopping malls", and nearly half of women may be attracted by advertising and blindly consume. Women play a subject position in the modern consumer, its consumption growth in order to promote the development of social economy has made a positive contribution, but also some conformity problem such as consumption, excessive consumption and wasteful, women more than men, random in the consumption of a lot of them want to buy what is what to buy, from real demand and consumption blindly, inevitably leads to waste, It is also not conducive to sustainable development.

Through the analysis of individual cases of female consumption in Xinrong District, we can understand the overall situation of rural female consumption in China, as well as the current situation of rural consumption as a whole. At present, China is in the critical period of building a well-off society. To improve female consumption rationality and overcome the problem of consumption alienation is an important process for building a conservation-oriented society and realizing sustainable economic development. Advocating civilized consumption and guiding people to consume moderately are very important to the sustainable development of society. In the future, online shopping will also walk into all aspects of people's life, such as clothing, food, housing and transportation. The new lifestyle will lead the new trend of female consumption. Advocating sustainable consumption, developing rational consumption and attaching importance to spiritual consumption are the invariable criteria for promoting sustainable economic development. Ai Yubo mentioned in her thesis on consumption alienation under the change of women's status in contemporary China, "Frugality is the common virtue; It is a great evil. Diligence and thrift is a traditional virtue of the Chinese nation. For individuals, thrift can nourish one's health. For families, thrift helps manage the house. For a party and a country, frugality can lead to better governance." [6] Rational consumption is not only the traditional virtue of the Chinese nation, but also the excellent moral character that the contemporary Chinese women should have. 


\section{Conclusion}

Since the implementation of rural revitalization, the rural economic level represented by the new prosperity area has been improved to varying degrees, and people's living standards have improved, income has increased, and consumption level has also been raised. It also promoted the status of women and made them the main force of the consumer market. However, there is still a serious gap between the rich and the poor between urban and rural areas in China. Compared with the national level, the living standard of rural residents in $\mathrm{Xi}$ nrong District, for example, has yet to be improved. Under the background of uneven development of urban and rural economic levels, to promote rural modernization and national modernization, we must implement the new development concept, effectively implement rural development policies, and adhere to the integrated development of urban and rural areas. So there is a need to continue to implement policies to promote economic development in rural areas and enable people to live a prosperous life. Rural revitalization is not only economic revitalization, but also ecological revitalization, social revitalization, scientific and cultural revitalization in an all-around way. It is necessary to promote economic development from a long-term perspective, effectively implement the rural revitalization strategy, lead contemporary women to consume rationally, reduce unnecessary waste, and realize a well-off society in an all-around way as soon as possible. As long as our farmers get richer, our countryside becomes more beautiful and our agriculture becomes stronger, we will achieve agricultural modernization and we will have hope for rural revitalization.

\section{Conflicts of Interest}

The authors declare no conflicts of interest regarding the publication of this paper.

\section{References}

[1] Liu, W.Y. (2012) Research on Influencing Factors of Residents' Consumption Decision-making from Microscale Perspective. Heilongjiang University Press, Harbin.

[2] Xinrong District People's Government of Datong. http://www.xr.gov.cn

[3] Marx (1975) The Complete Works of Marx and Engels (Volume 3). People's Publishing House, Beijing.

[4] Zhang, H. (2011) The Woman Wins the World. Zhongxin Publishing House, Beijing.

[5] Zhang, H.L. (2006) Research on Women's Consumption. Master Dissertation, Central China Normal University, Wuhan.

[6] Ai, Y.B. (2016) Research on Consumption Alienation under the Change of Women's Status in Contemporary China. Ph.D. Dissertation, Jilin University, Changchun. 